\title{
Labyrinthe
}

23 | 2006 (1)

Quatre chercheurs de l'étranger

\section{Ashley Thompson : généalogies de la mémoire}

\section{Laurence Marie}

\section{(2) OpenEdition}

\section{Journals}

Édition électronique

URL : http://journals.openedition.org/labyrinthe/1152

DOI : $10.4000 /$ labyrinthe. 1152

ISSN : 1950-6031

Éditeur

Hermann

\section{Édition imprimée}

Date de publication : 15 janvier 2006

Pagination : 11-13

ISBN : 2-9526131-0-9

\section{Référence électronique}

Laurence Marie, "Ashley Thompson : généalogies de la mémoire », Labyrinthe [En ligne], 23 | 2006 (1), mis en ligne le 23 juillet 2008, consulté le 20 avril 2019. URL : http://journals.openedition.org/ labyrinthe/1152 ; DOI : 10.4000/labyrinthe.1152 


\section{Ashley Thompson : généalogies de la mémoire}

Laurence MARIE

En 1985, alors qu'elle passe une année en France dans le cadre de ses études à Harvard, l'Américaine Ashley Thompson assiste à la pièce d'Hélène Cixous, L'Histoire terrible mais inachevée de Norodom Sihanouk, roi du Cambodge, jouée au Théâtre du Soleil d'Ariane Mnouchkine. Le spectacle de la tragédie cambodgienne la marque profondément. À son retour à Boston, elle décide, tout en poursuivant ses études, d'enseigner l'anglais dans un quartier peuplé de boat people d'Asie du Sud-Est. Puis, à la fin des années 1980, c'est le départ pour Site 2 , camp de réfugiés installé à la frontière thaïlandaise suite à l'occupation vietnamienne. Dépêché sur place, un groupe de psychiatres étrangers interroge inlassablement les exilés, déterminé à aider ceux dont la culture refoule toute manifestation de tristesse à surmonter les séquelles du génocide. Faux remède, réplique Ashley Thompson: le travail de deuil suit son cours, lentement, souterrainement. Seulement, l'Occidental ne sait pas en lire les signes.

Ces rencontres et ces malentendus entre l'Orient et l'Occident inspireront à Ashley Thompson un DEA au Centre de recherches en études féminines de l'université de Paris VIII: «La Ville assiégée: Site 2 » (1991). Non contente de maîtriser parfaitement le français, celle qui, à Harvard, s'intéressa d'abord aux représentations de la guerre du Vietnam, s'attèle alors à l'apprentissage du khmer, du pali et du sanskrit. Un autre mémoire, en études indiennes cette fois, et à l'université de Paris III («Le hau bralin: étude du rite et du texte » en 1993), vient confirmer son intérêt pour la mémoire collective qui surgit de la parole et des écrits asiatiques.

Ses diplômes américains et français en poche, la jeune femme s'envole pour le Cambodge. Elle y demeure de 1994 à 2000. Munie d'une bourse de recherche doctorale du Social Science Research Council, elle recueille les traces écrites des croyances et des pratiques religieuses 
visibles dans les sites archéologiques de la région d'Angkor et des capitales postangkoriennes: elle soumet les inscriptions de stèles, les manuscrits, les légendes orales ou les récits ethnographiques à un examen minutieux empruntant ses méthodes à l'histoire, l'ethnographie, l'épigraphie et l'iconographie. Entre deux expéditions de fouilles, Ashley Thompson enseigne à la faculté d'archéologie de Phnom Penh et travaille auprès du ministre cambodgien de la Culture pour établir un organe national de protection et de gestion du patrimoine et organiser la formation des jeunes khmers en archéologie et en ethnologie. Ces activités diverses conduisent à deux livres - Angkor: a Manual for the Past, Present and Future (Apsara: Unesco 1995, avec Ang Chouléan et Eric Prenowitz), et Danse in Cambodia (Oxford University Press, 1999, avec Toni Samantha Phim) - ainsi qu'à des articles consacrés aux cultes indiens et indigènes en Asie du Sud-Est, à la possession spirituelle et au bouddhisme dans le Cambodge moderne. Les réflexions engagées ici et là feront naître un travail de thèse examinant une période tombée dans l'oubli: «l'Époque moyenne », qui débute vers le XIII siècle, au lendemain de l'apogée de l'empire d'Angkor, et se termine lors du rétablissement du protectorat français en 1853 . Ce n'est pas un hasard si ces « Mémoires du Cambodge » sont dirigées par Hélène Cixous, l'initiatrice.

À son retour, Ashley Thompson obtient dans la foulée un poste d'Assistant Professor au département d'Asie et d'Asie du Sud-Est à Berkeley. En 2003-2004, elle anime au Centre de recherches en études féminines de Paris VIII deux séminaires sur la différence sexuelle en Indochine et sur les rapports entre la femme et la déconstruction du bouddhisme. Elle enseigne aujourd'hui à l'université de Leeds en Grande-Bretagne dans le département de la School of Fine Art, History of Art and Cultural Studies.

Les « Mémoires du Cambodge » s'interrogent sur la transmission de l'héritage angkorien par le biais d'une analyse textuelle précise des cultes religieux et des représentations de l'Époque moyenne. Plus largement, elles montrent comment la fabrication de l'histoire est modelée par la différence sexuelle et s'engendre à partir de sources historiques partiellement fictives et de sources non scientifiques révélatrices d'une certaine vérité. Ce faisant, elles ouvrent la voie à une réflexion sur le statut des sources comme mémoire et comme archives à interpréter, et sur le rapport que l'historien entretient avec elles. 
La construction des discours historiographiques formulés pendant l'Époque moyenne et à propos d'elle joue un rôle essentiel dans l'affirmation de l'unité khmère aujourd'hui. Les chercheurs occidentaux ont en effet longtemps suggéré que la culture avait disparu après la chute de la civilisation angkorienne au $\mathrm{XV}^{\mathrm{e}}$ siècle et ne serait réapparue qu'au début du $\mathrm{Xx}^{\mathrm{e}}$. Par leurs fouilles extensives, ils se sont arrogé le privilège de restaurer la mémoire de l'empire d'Angkor et de restituer à un peuple son passé enseveli sous la jungle. Ils ne sont pas les premiers à se livrer à l'exercice: avant eux, au XVI' siècle, un roi prétend «redécouvrir» Angkor. Les textes produits à l'époque préfigurent la dialectique de la perte et du recouvrement de la mémoire qui sera celle des colonisateurs français, à leur tour «redécouvreurs» d'Angkor à la fin du XIX ${ }^{\mathrm{e}}$ siècle. Les formes prises par cette transmission mémorielle que s'est appropriée l'Occident mettent en jeu l'identité du peuple cambodgien avec une acuité d'autant plus grande qu'il a vu sa culture anéantie et sa langue déstructurée par le génocide perpétré entre 1975 et 1979. Ce n'est pas le moindre des intérêts de la démarche d'Ashley Thompson que de chercher à penser ensemble ces différents phénomènes, à travers un cheminement historique composé d'allers et retours féconds entre le passé et le présent. Les premières pages des « Mémoires du Cambodge », écrites en français et non publiées à ce jour, parleront d'elles-mêmes, mieux que toute reformulation extensive ne saurait le faire. 